\title{
The cost structure of influencers' posts: the risk of losing followers
}

\author{
Carlos Oliveira $^{1}$ (D) . Ana Cristina B Garcia ${ }^{1}$. Adriana S Vivacqua ${ }^{1}$
}

Received: 14 August 2019 / Accepted: 1 December 2020 / Published online: 20 January 2021

(C) The Author(s), under exclusive licence to Springer-Verlag London Ltd. part of Springer Nature 2021

\begin{abstract}
This paper presents an exploratory study of the posting behavior of digital influencers in social participation platforms. As there are different platforms of social participation, we present a taxonomy to unify the different classifications and delimit the scope of our work. Influencers could produce a positive externality of increasing participation by suggesting social causes and government actions they believe in. However, influencers tend to restrict their posts to the domain subject they became popular for. Our goal is to identify the cost structure of posting behavior of influencers, from the desire to post to the actual act of posting. The findings indicate the two key factors influencers consider when posting are (a) the risk of losing followers and (b) the effort required to verify the information. On the other hand, followers indicate they like it when influencers voice their opinion on social causes. These findings are anchored on social influence theory. We also found different factors that motivate/demotivate people to post on social media. We noticed that the factors that will motivate a user to post can either be aroused in him (i.e., already internalized in the person) or can be "planted" in the person (i.e., from outside).
\end{abstract}

Keywords Social participation $\cdot$ Social media $\cdot$ Digital influencers $\cdot$ Social causes $\cdot$ Post behavior $\cdot$ Motivating factors

\section{Introduction}

Social networks now have billions of users worldwide. These systems allow people to keep in touch with friends and relatives, overcoming distance. They also allow people to peek into each other's lives. The large audience of social networks allowed previously unknown people to have a large audience. The term "digital influencer" then appears. Digital influencers are people who can influence the behavior and opinion of others through the content they publish on their social networks [1]. Influencers need followers to be called influencers. Followers trust influencers' opinions. Followers are always looking for and consuming content produced by influencers, whose recommendations nudge their digital and real-life behaviors. Influencers often serve as a marketing aid for selling products and ideas.

In recent years, several governments have created electronic participation platforms so that citizens can participate in government decisions. However, there is still low citizen participation on these platforms [2]. The participation of citizens using digital media (e-participation) improves the

Carlos Oliveira

carlos.roberto@uniriotec.br

1 UFRJ, Rio de Janeiro, Brazil effectiveness of government decision-making since it gives credibility to the decisions and a sense of citizen awareness of what is going on. e-Participation increases opportunities for citizens to participate in government policy-making. Participation may also minimize distortions in the government's understanding of the needs and preferences of its citizens, as well as legitimize government decisions and improve citizens' trust in government since they perceive the government to be more transparent and responsive [3].

Although people have fought for greater participation, now that the government is creating the means for mass participation, people are neglecting to exercise their rights. The methodologies and technologies for supporting popular participation are among the Great Challenges of Research in Information Systems in Brazil (2016-2026) [4]. This happens because citizen participation is an increasingly urgent need in modern societies, but the mobilization of citizens is still a challenge.

Increasing citizen participation has been for a long time a challenge for e-government researchers. Following the social network trends, spreading the news through posts by digital influencers is effective for reaching massive public attention. The great power of influencers to guide people's behavior has been used by a marketing campaign to effectively increase sales. The herding effect caused by influencers could be used to foster citizens' participation in public affairs. This seems an obvious idea, but it is rarely the 
case that influencers post public utility information. What prevents or encourages influencers to publish public utility information, especially those connected to governmental issues? How does the intention to post increase? What are the technological barriers or speedups to encourage influencers to post public utility information?

We conducted an exploratory study to better understand the influencer-follower relationship, especially the cost structure of influencers' online posting behavior. Instead of doing a broad investigation, we focus our study on citizenship-related posts for three reasons:

1. Some influencers have become wealthy with social media. However, others, despite having many followers, have not become rich yet, for example, the influencer "Favelado Investidor,"1 who still lives in a slum in Rio de Janeiro and has 190 thousand followers, and the influencer "Nath Finanças," also a slum resident with 408 thousand followers ${ }^{2}$ (a 21-year-old student who gives investment tips to the low-income public). Therefore, these influencers face the same social issues as their followers;

2. The rate of online citizen participation in the government issues is extremely low, even though the government offers multiple communication channels for that; and

3. The premise that influencers opinions and suggestions have the powers of nudging followers' behavior [1].

Looking at Brazilian influencers' posts, we observed that, except for journalist or politicians, they never talk about their actions as citizens. ${ }^{3}$ Although many influencers interact with government platforms to sign a petition, get useful information or services, or discuss a law proposal, they restrict their posts to subjects they became known for. Looking for the great positive externality, their posts on citizenship-related subjects could provide by leading more people to participate and, consequently, fomenting a robust democracy, we want to understand the factors preventing this and to draw guidelines for designing a layer of technology to minimize the effects of these factors. Specifically, our research aims to (1) understand whether influencers would post about social causes and what the perceived costs are for that; (2) understand what the followers' reaction to these posts would be. This paper is organized as follows. Section 2 presents taxonomies for participation platforms and digital influencers. Our research methodology is presented in Section 3. Section 4 presents

\footnotetext{
$\overline{{ }^{1} \text { https://twitter.com/faveladoinvest }}$

${ }^{2}$ www.youtube.com/c/NathFinancas/about

${ }^{3}$ https://medium.com/observatorio-de-midia/jornalistas-como-influenc iadores-digitais-c69554894f31
}

the results. A discussion of results is presented in Section 5 . Section 6 concludes the article and outlines future work.

\section{Background}

The objective of our research is to understand the factors that foster or prevent digital influencers to post content related to citizens' e-participation. To create a better understanding of our research context, we present an eparticipation taxonomy that describes the different levels of e-participation. Afterwards, we define digital influencers, specifying the two types of digital influencers.

\subsection{An e-participation taxonomy for Brazilian digital democracy}

Most e-participation taxonomies put information delivery and services as the basic layer. This first layer is oneway communication in which citizens can only reach information, such as new laws and norms, and services, such as getting a negative certificate of debits, that may affect them. Research differs in the number of layers and the expectation of public participation.

Howard [5] divides e-participation into three layers of participation, namely government information displacement, basic interaction through emails, chats or surveys, and public services. Chandler and Emanuels [6] add one more layer related to government services and information integration to facilitate citizens' reach. Layne and Lee [7] offer a similar taxonomy; however, they differentiate government vertical (city, state, country) and horizontal (different services within the same government hierarchy) integration. The United Nations [8] also presents a taxonomy for e-participation composed of five different levels. In the first, the government makes limited information available online without an expected update frequency. In the second level, the government commits itself to regularly update the displayed information. In the third level, the government offers a reasonable level of interaction, allowing them to download forms and upload information. In the fourth layer, the government offers complete services that require citizens' interactions such as obtaining visas, licenses, passports, birth, and death records. In the fifth stage, it provides services in all administrative and departmental lines with the highest level of integration. Macintosh [9] characterizes e-participation, based on a report by the OECD [10], according to the means to be informed, the mechanisms to participate in the government decision-making, and the contribution and influence to the political agenda.

Cunha et al. [11] performed a literature review and reached a taxonomy composed of four different levels of interaction between citizens and government: government 
Fig. 1 e-Participation classification, technologies, and challenges imposed by each layer of e-participation

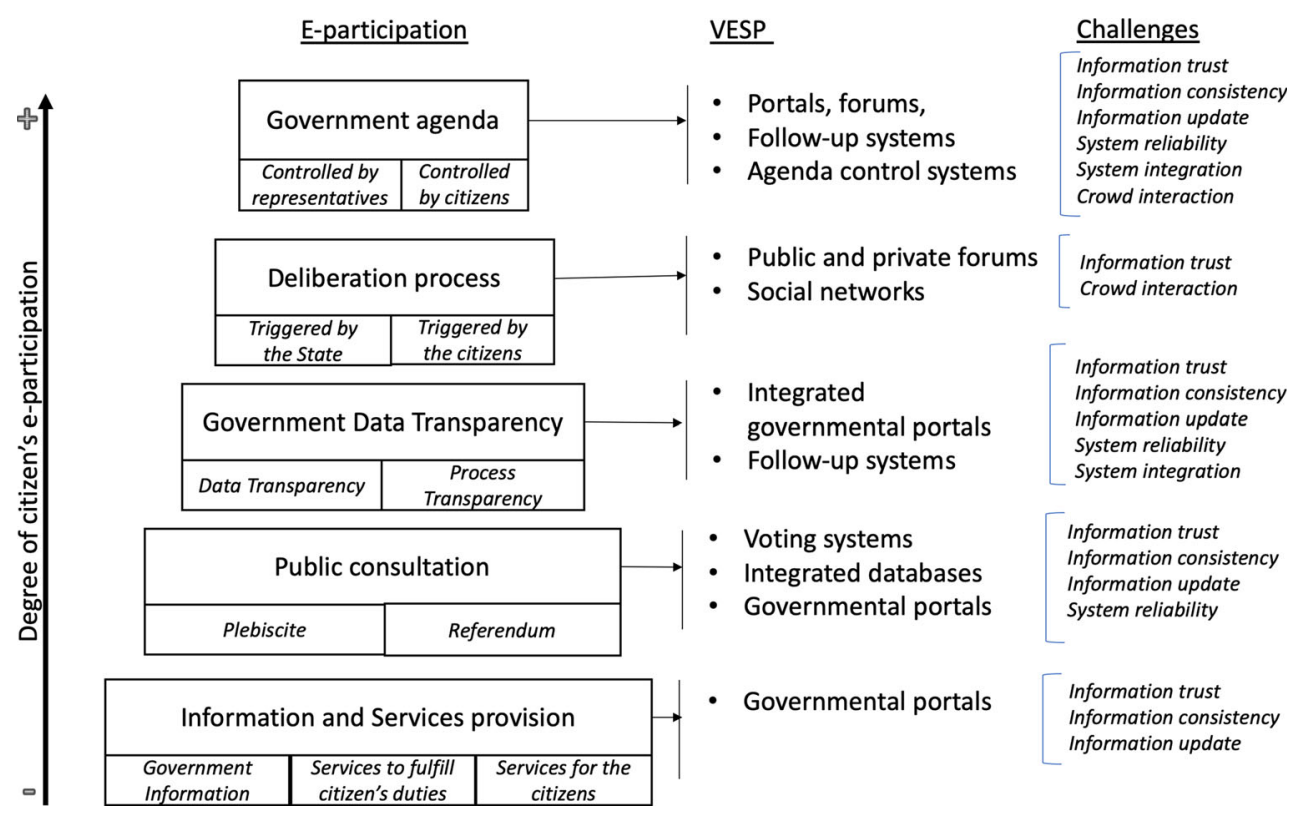

information supply, government communication channel supply, government stimuli to citizens' participation and citizens' empowerment. Pinheiro [12] takes another perspective to categorize e-participation, as follows: (1) Who are the responsible actors for the initiatives? (2) Why was the participation channel developed and why is it online? (3) How do these e-participation platforms enable political practices? (4) In what spheres of government is it possible for the citizen to act when using the platforms?

In 2014, the Brazilian federal government instituted decree $8.243^{4}$, regulating the national policy of social participation. The decree's focus is to foster social participation in government decision-making. According to the decree, the government should develop social interaction mechanism using information and communication technologies (ICTs), taking advantage of the successful use of the Internet and social media, to build Virtual Environments of Social Participation (VESP). VESP fosters the dialogue between federal public administration and civil society. However, it is not clear what is meant by VESP. There are many types of citizens' participation, in many different contexts and with different purposes. To shed light on VESP potential types of participation, we expand Gomes [13] e-participation taxonomy making it more concrete and workable for the Brazilian digital democracy.

According to Gomes [13], citizen e-participation takes place in five different levels of interaction, in a digital democracy. The first level accounts for the provision of services and information by the State. The second level accounts for the citizens' participation in the government

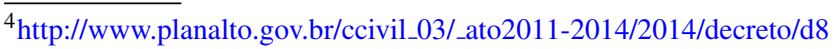
243.htm
}

public consultations. The third level accounts for the government opening their data and process: transparency for the citizen. The fourth level accounts for including citizens in the government deliberation process. The "Utopian" fifth level accounts for the total control of the State by the citizens.

We expanded Gomes [13] taxonomy, based on thorough literature reviews and descriptions of e-participation systems. Figure 1 illustrates the new detailed categories, which are further described in Table 1. This classification better defines and specifies different forms of participation, specifying the technological elements and challenges. The technological elements included in the taxonomy description explain the mechanisms for interaction between government and citizens. We expect that this detailed definition helps to better classify the level of e-participation, especially fit for Brazil. Specifically, our research focuses on citizen-initiated deliberation processes (presented in the fourth level).

\subsection{Why should we care: Evidences of low e-participation in Brazil}

Several initiatives have been taken by the Brazilian government to enable citizens to be more participative and involved in decision-making. We can mention the various virtual environments of social participation that were created within a Brazilian context, such as Dialoga Brasil, ${ }^{5}$ Participa.br ${ }^{6}$, and Legislative Idea. ${ }^{7}$

\footnotetext{
$\overline{5 \text { http://dialoga.gov.br }}$

${ }^{6}$ http://participa.br/

${ }^{7}$ https://www12.senado.leg.br/ecidadania/principalideia
} 
Table 1 Levels of digital democracy

Category Definition

Provision of services

Participation through consultation

Transparency

Deliberative participation

Citizen controls state
Definition: State action to provide information and meet the demands of society regarding the exercise of a right or the performance of a duty. Such provision of services and information may take place through portals or applications. Note: The provision of information is not for the citizen to supervise the State, this information can even serve as a platform for self-promotion by governments.

Subcategories:

1. Provision of services for the exercise of rights;

2. Provision of services for the fulfillment of duty;

3. Provision of information.

Definition: Action to consult the citizen to inquire about public agenda issues and, eventually, the formation of the public agenda. States or administrators should organize systems for public discussion of important projects and enable consistency checks and public examination and debate. Deliberation should depend on the public agent. In the context of the Brazilian government, the eDemocracy portal (www.edemocracia.leg.br) aggregates other portals for legislative participation. This participation can be done by sending questions of the citizen to the politician, with proposals to edit laws, in discussions that can be initiated by the citizens themselves and through voting. The Internet also allows the consultation to be done by surveys.

Subcategories:

1. Consultation by vote;

2. Consultation by discussion;

(a) Consultation by discussion in forums;

(b) Consultation by discussion in social networks.

\section{Consultation by poll.}

Definition: Providing information on how public money is being used, in addition to issues related to public management in Brazil. In the context of the Brazilian government, this information is made available through the Transparency Portal (http://www.portaltransparencia.gov.br/). In this case, the State provides services, information, and accounts to citizenship, but does not rely on it for the production of political decision.

Subcategories: -

Definition: Action or effect of participating in a discussion whose purpose is to solve a problem. This discussion can take place through portals, applications, or social networks. Gomes [13] states that "deliberative democracy combines the model of participatory democracy with the model of representative democracy" [13]. In this case, public deliberation uses electronic means of argumentative interaction.

Subcategories:

1. Presentation of ideas by the State;

2. Presentation of ideas by the citizen.

(a) Ideas sent from the citizen to the State;

(b) Ideas exchanged between citizens.

Definition: Control of political decisions by the citizen. At this level, the professional political sphere would be extinguished because the public would even control the political decision within the State. The result of the establishment of a fifth-degree digital democracy would be, for instance, a state governed by online plebiscites in which the public sphere would be exclusively for the public administration.

Subcategories:

1. Control by voting.
Through access to the Law of Information, ${ }^{8}$ we requested data on citizen participation in these environments from

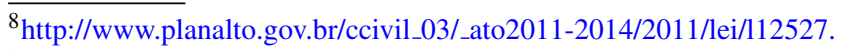
htm the Federal Executive Branch. The National Secretariat for Social Articulation, which is responsible for the Participa.br and Dialoga Brasil websites, informed us that these portals were launched in 2014 and 2015, respectively. However, the Secretariat did not have a historical series of 
annual participation in these environments, only the data for July 20, 2018, which is when they gave us the data. On that day, there were 4364 registered users on the Participa.br site. The Secretariat also informed us that from its inception up until that moment, the site had received 13,600,792 visits. The Secretariat stressed that it does not promote a study on effective citizen participation and the portal is not prepared to produce this information. In other words, the informed access number only means that citizens have accessed the site, not that they have published or issued an opinion on any public consultation.

Concerning Dialoga Brasil, the Secretariat informed that this website was launched in 2015 and has not had any activities since 2016. The latest site numbers were published in the management report of the Brazilian Court of Auditors in 2016, as follows: total of 293,298 site visits; 236,996 users and 17,344 proposals. We also accessed information made available by the Legislative Branch regarding the Legislative Idea website. ${ }^{9}$ On this site, any citizen can make a proposal for a legislative idea. The legislative ideas have a period of 4 months to receive a support level of 20,000 from other Internet users. Those who receive this number of supports are referred to the Commission on Human Rights and Participatory Legislation, where they will be debated by senators and will receive an opinion. Over 7 years, a total of 51,143 ideas were registered on the site. In the year that most proposals were made (2017), 18,529 people made proposals. It should be noted here that Brazil has over 200 million citizens, so we are far below $1 \%$ citizen e-participation. (Cruickshank et al. [14] argue that 1\% of popular participation is a successful result for democracy.)

\subsection{Influencers in social networks}

Social networks can be described as the virtual worlds in which individuals have the opportunity to choose a new identity and freely share knowledge, opinions, and views with other people [15]. Social network analyses help identify interaction patterns that connect social actors [16]. Social networks have the potential to substantially impact word-of-mouth marketing. Studies have demonstrated that word-of-mouth and peer recommendations have an effective effect on sales when the news is spread by influencers, which works as an effective form of advertising [17]. Sanchez-Cartas and Leon [18] simulated a theoretical market in which two digital platforms compete for users and developers during the launch phase of these platforms. They observed that digital platform adoption is greater and faster as influencers join the platform as users. Without influencers, the adoption and the speed of adoption are much smaller. Thus, the ability

\footnotetext{
${ }^{9}$ https://www12.senado.leg.br/ecidadania/documentos/home/resultados
}

to identify influencers in social networks is valuable in the context of electronic word-of-mouth (eWOM). Marketing information is propagated quicker and better promoted through recommendations from influencers in social networks to their followers [19]. Using digital influencers is a marketing strategy used not only to sell brands and products but also to propagate ideas in social participation platforms, commonly used in election campaigns.

There is no consensus in the literature concerning influencers' classification. Neves et al. [20] pointed out three main difficulties to come up with a consensual influencers' taxonomy. First, it is not clear what relevant features identify a person as an influencer. While some studies explore the social structure of networks, others focus on patterns of network propagation or basic statistics individual online behavior [21], such as the number of posts replicated by their contacts and the total number of answered messages. The second difficulty is the way to determine the individual attributes of influencers related to specific objectives, such as economic and social, background, and information accessibility, they have empowered by their social and professional connections. Last, but not least, there is the difficulty of identifying effective metrics to identify influencers in each domain.

Neves et al. [20] proposed three methods for identifying influencers. The first method involves analyzing individuals' network structures and, based on sociological theories, use PageRank [22] and Principal Component Centrality (PCC) [23] to determine the probability of being an influencer. The second method refers to strategies focused on the posts' content and flow. This method is the mathematical modeling of the problem. Studies on this group range from statistical analysis of activity record to strategies based on graphs. This class is represented by ProfileRank [24] and Effective Readers [25] strategies. The third method consists of strategies that explore the statistical summary of user actions and attributes. The strategies of this group are based on economic theories. Theories of this group are usually focused on viral marketing and brand adoption. The goal is to understand the mechanisms that lead to a large-scale chain reaction of influence, with a very small marketing cost. Strategies belonging to this class are the number of followers [26] and number of retweets [17].

The number of followers alone may be misleading because there might be a "scratch my back and I will scratch yours" strategy. According to Yang et al. [27], the following/followed relation is a good metric to measure the range or prestige of a follower. This has also been observed in our study since those influencers with millions of followers usually follow only a few people. People with thousands of followers that follow thousands of people might not be an influencer. The number of retweets is also 
Fig. 2 Methodology used in this work

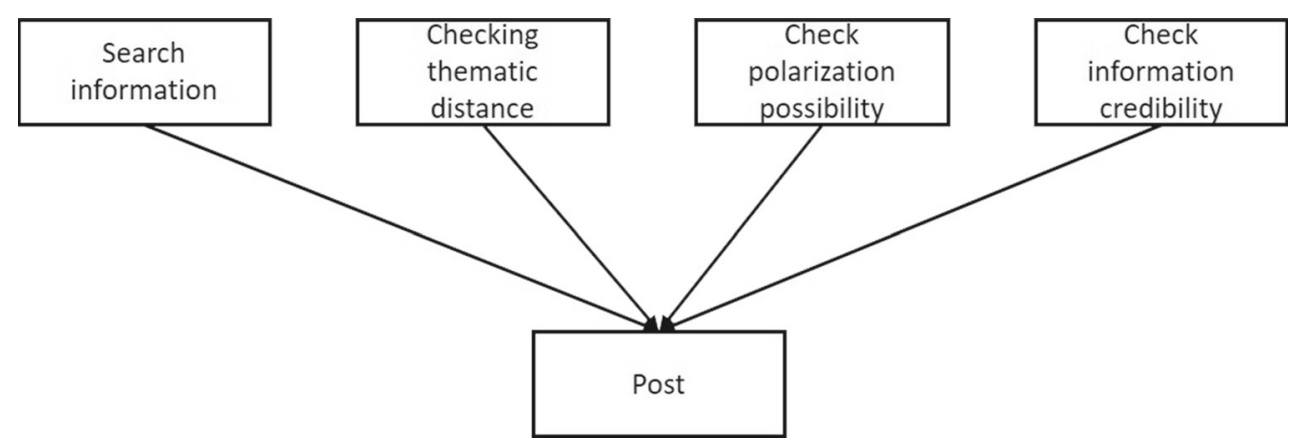

an important metric because it measures the strength of the influencer over the follower. The greater the number of retweets, the greater the chances the idea/product becomes viral. Although there is no consensus in the literature on how to define whether a person is an influencer or not [20], in general, influencers are much more followed than others [27].

Thus, one of the metrics for defining an influencer is the number of followers [20]. In Brazil, users have an average of 231 followers on social media. ${ }^{10}$ Only influencers with more than a thousand followers and who have at least 10 times more followers than people they follow were invited to participate in this research.

\section{Research methodology}

\subsection{Motivation for the experiment}

The objectives of the experiment were to understand if the influencer would post about social causes and the reasons for followers to follow someone on social networks, in addition to collecting evidence of situations in which they were influenced by the influencers' opinions. Also, we need to do these interviews as a way of checking whether the questions, which we would later ask a wider audience, were understandable and would allow us to understand whether the influencer would post about social causes and how followers would react to these posts. Figure 2 shows the methodology used in this work.

\subsection{Interviews with participants for the preparation of questionnaires}

Initially, we interviewed an influencer who is part of our research group. $\mathrm{He}$ is 57 and works as an information systems manager at a public cancer hospital. He returned

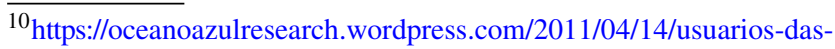
redes-sociais-do-pais-tem-media-de-231-seguidores-contra-120-da-me dia-global/
}

to university last year for a doctorate. He is also a writer of thriller books. He wrote 3 books, several poems, and two plays. Although it is his passion, writing has always been a hobby, as he does not sell enough to support him economically. He has more than 30,000 followers on social media because of his books. He frequently posts, at least once a week, subjects related to the characters of his new books or themes related to the understanding and discussion of his published books. His followers are adults of varying ages. We also interviewed three other members, two men and one woman, from our research group considered to be followers of other people on social networks. The interviews were conducted in person (and individually) and each question was read to the interviewee. We note that the only participation that these individuals had in this research was in this interview.

\subsection{Description of interviews/questionnaires}

This set of interviews helped us create an online questionnaire to collect data from randomly selected influencers (shown in Appendix 1) and followers (shown in Appendix 2), but that meet the requirements we have outlined for influencers (having more than a thousand followers) and followers (follow influencers on social networks). Also, we have included questions to see if followers would check an influencer's suggestion for accessing virtual environments of social participation.

\subsection{Participants who answered questionnaires and interviews}

One hundred and thirty-eight Brazilian influencers, chosen randomly on Twitter, were invited to answer the questionnaire. These 138 influencers have between thousands and millions of followers in Brazil. Given the difficulty in getting people to answer the questionnaire, we invited other influencers within the social reach of our research group (friend of a friend of a friend) who met the requirements to participate in our survey. As a result of our strategy of inviting influencers, 165 digital influencers were invited to answer the questionnaire. 
We also invited the followers of these influencers to answer another questionnaire. Likewise, given the difficulty of getting people to answer the questionnaire, other people were invited by WhatsApp groups and by the email list of university graduate students. As a result of our strategy of inviting followers, 310 people were invited to answer the questionnaire for followers. We aimed to verify whether (1) influencers would be willing to influence their followers to participate in platforms that defend the causes of social and what were the costs (in the sense of onus) perceived by the influencer for this; and (2) whether the follower would accept to participate in electronic participation platforms suggested by the influencer. We developed two online questionnaires to get answers to our research questions, one sent to influencers and the other sent to followers. The questionnaires were available online from February 17 to March 6, 2019. None of the participants received any compensation for participating in the survey. Table 2 shows the data for the influencers and Table 3 shows data for followers in the three stages of this research. As can be seen, 39 people participated in the different stages of this research. The occupation and number of followers were not asked for the followers who answered the questionnaire in stage 2. We also did not ask how many people the influencers followed (on stage 2).

\subsection{Data analysis}

The purpose of data coding was to map the "raw" data (shown in Appendix 3) from the interviews into a set of costs perceived by the influencer to post on platforms that have social causes. To analyze these data, we used Grounded theory. The analysis steps involved open coding, axial coding, and selective coding [29]. In the first step (shown in the first column of Table 4), the initial codes emerged by reading each transcript line by line. In the second step (shown in the second column of Table 4), we differentiate the codes resulting from open coding. In this step, we name categories to describe a central phenomenon that is happening. In the third step (shown in the third column of Table 4), the goal is to integrate and refine categories on a more abstract level. The task is to elaborate on the essential category, around which the other developed categories can be grouped and by which they are integrated. According to Strauss and Corbin [30], "the central phenomenon is at the heart of the integration process." In this work, theoretical saturation occurred.

In Grounded theory, saturation is achieved when the analyzed concepts (costs for posting social causes) can already be understood and proven by the data [31]. In the end, the codes were then synthesized into four coherent categories/costs (search information, checking thematic distance, check polarization possibility, and check information credibility). Table 4 presents some examples of codes found.

\section{Research findings}

Six of the 165 invited influencers answered the questionnaire. Twenty-seven out of 310 invited followers responded. This low adherence can be explained by the theory of planned behavior [32]. The performance of most behaviors depends, at least to some extent, on non-motivational factors, such as the availability of needed opportunities and resources (time, money, skills, etc.).

\subsection{Influencers}

The posting of a message on social media is preceded by tasks, which must be performed by the influencer and were investigated in this work. Therefore, these tasks are inherent burdens of posting social causes to social media. Different influencers will act differently in the face of these tasks. We could observe that there is no consensus to classify influencers [20]. In this work, we made a previous analysis of the 165 influencers invited to participate in this research. Later, we studied the behavior of those six influencers who actually participated. We noted, when it comes to posting social causes, influencers can be divided into two distinct types. These observations were valid not only for the six influencers who participated in this research, but also for the 165 influencers who were asked to answer the questionnaire that could also be classified into one of these two types. These two types of influencers are businessoriented influencers (type 1) and idea-oriented influencers (type 2). For type 1 influencer, followers are their main asset and would be very careful not losing them. The number of followers has a direct impact on their economic profits as an influencer. Therefore, type 1 influencers seek to increase the number of followers when posting. They always make a trade-off analysis considering the economic upfront gains with the risk of losing their followers. They avoid polarization or information that escapes from the welcomed content their followers are expecting. They are careful when posting social causes for not causing rejection.

For type 1 influencer, followers are their main asset and would be very careful not to lose them. The number of followers has a direct impact on their economic profits as an influencer. Therefore, type 1 influencers seek to increase the number of followers when posting. They always make a trade-off analysis considering the economic upfront gains with the risk of losing their followers. They avoid polarization or information that escapes from the welcomed content their followers are expecting. They are careful when posting social causes for not causing rejection. 
Table 2 Influencers' data description

\begin{tabular}{|c|c|c|c|c|c|c|}
\hline ID & Age & Gender & Occupation & Number of followers & Research method & Study phase \\
\hline 1 & 57 & M & $\begin{array}{l}\text { CS manager } \\
\text { and } \\
\text { book writer }\end{array}$ & $\sim 30 \mathrm{k}$ & $\begin{array}{l}\text { Semi- } \\
\text { structured } \\
\text { interview }\end{array}$ & $1,2,3$ \\
\hline 2 & 30 & M & Blogger & $\sim 151 \mathrm{k}$ & $\begin{array}{l}\text { Semi- } \\
\text { structured } \\
\text { interview }\end{array}$ & 2,3 \\
\hline 3 & 36 & $\mathrm{~F}$ & Publicist & $\sim 20 \mathrm{k}$ & Questionnaire & 2 \\
\hline 4 & 21 & $\mathrm{~F}$ & Youtuber & $\sim 5 \mathrm{k}$ & Questionnaire & 2 \\
\hline 5 & 40 & $\mathrm{~F}$ & Artist & $\sim 30 \mathrm{k}$ & Questionnaire & 2 \\
\hline 6 & 29 & $\mathrm{~F}$ & Lawyer & $\sim 10 \mathrm{k}$ & Questionnaire & 2 \\
\hline
\end{tabular}

Table 3 Followers data description

\begin{tabular}{|c|c|c|c|c|c|}
\hline ID & Age & Gender & Follows & $\begin{array}{l}\text { Research } \\
\text { Method }\end{array}$ & $\begin{array}{l}\text { Study } \\
\text { Phase }\end{array}$ \\
\hline 1 & 33 & $\mathrm{~F}$ & Between 100 and 500 & Interview & 1 \\
\hline 2 & 36 & M & Between 500 and $1 \mathrm{k}$ & Interview & 1 \\
\hline 3 & 32 & M & Between 500 and $1 \mathrm{k}$ & Interview & 1 \\
\hline 4 & 34 & $\mathrm{~F}$ & Between 100 and 500 & Quest. & 2 \\
\hline 5 & 29 & $\mathrm{~F}$ & Between 500 and 1000 & Quest. & 2 \\
\hline 6 & 63 & M & Up to 50 & Quest. & 2 \\
\hline 7 & 36 & M & Between 100 and 500 & Quest. & 2 \\
\hline 8 & 38 & M & Between 100 and 500 & Quest. & 2 \\
\hline 9 & 41 & $\mathrm{~F}$ & Up to 50 & Quest. & 2 \\
\hline 10 & 34 & M & Between 500 and $1 \mathrm{k}$ & Quest. & 2 \\
\hline 11 & 60 & M & Between 500 and $1 \mathrm{k}$ & Quest. & 2 \\
\hline 12 & 34 & M & Between 50 and 100 & Quest. & 2 \\
\hline 13 & 28 & M & Between 500 and $1 \mathrm{k}$ & Quest. & 2 \\
\hline 14 & 29 & $\mathrm{~F}$ & Between 500 and $1 \mathrm{k}$ & Quest. & 2 \\
\hline 15 & 35 & M & Between 500 and $1 \mathrm{k}$ & Quest. & 2 \\
\hline 16 & 29 & $\mathrm{~F}$ & More than $1 \mathrm{k}$ & Quest. & 2 \\
\hline 17 & 30 & M & Between 500 and $1 \mathrm{k}$ & Quest. & 2 \\
\hline 18 & 49 & $\mathrm{~F}$ & Between 50 and 100 & Quest. & 2 \\
\hline 19 & 31 & $\mathrm{~F}$ & Between 100 and 500 & Quest. & 2 \\
\hline 20 & 26 & M & More than $1 \mathrm{k}$ & Quest. & 2 \\
\hline 21 & 55 & $\mathrm{~F}$ & Between 50 and 100 & Quest. & 2 \\
\hline 22 & 33 & $\mathrm{~F}$ & Between 100 and 500 & Quest. & 2 \\
\hline 23 & 31 & M & Between 100 and 500 & Quest. & 2 \\
\hline 24 & 56 & $\mathrm{~F}$ & Between 50 and 100 & Quest. & 2 \\
\hline 25 & 56 & M & Between 100 and 500 & Quest. & 2 \\
\hline 26 & 53 & M & Up to 50 & Quest. & 2 \\
\hline 27 & 25 & $\mathrm{~F}$ & Between 500 and $1 \mathrm{k}$ & Quest. & 2 \\
\hline 28 & 23 & M & Between 50 and 100 & Quest. & 2 \\
\hline 29 & 34 & M & Up to 50 & Quest. & 2 \\
\hline 30 & 19 & M & More than $1 \mathrm{k}$ & Quest. & 2 \\
\hline 31 & 36 & $\mathrm{~F}$ & Between 50 and 100 & Quest. & 3 \\
\hline 32 & 30 & $\mathrm{~F}$ & Between 500 and $1 \mathrm{k}$ & Quest. & 3 \\
\hline 33 & 29 & M & Up to 50 & Quest. & 3 \\
\hline
\end{tabular}


Table 4 Coding examples from influencers interviews

\begin{tabular}{|c|c|c|c|}
\hline ID & Open coding phase & Axial coding phase & Selective coding phase \\
\hline 1 & $\begin{array}{l}\text { Suppose you have a petition to build an artificial } \\
\text { fund in Marica (city in Rio de Janeiro). I found it } \\
\text { super interesting because it will promote tourism, } \\
\text { it will bring economic opportunities. This is a } \\
\text { petition that I would post on my Instagram, which } \\
\text { I think is valid. It is a cause or something related } \\
\text { to my beliefs and also related to my audience. }\end{array}$ & Check followers' interest & Verify thematic distance \\
\hline 1 & $\begin{array}{l}\text { I have already divulged the social cause of an } \\
\text { acquaintance from Africa, who is building a } \\
\text { school. But I am very careful to divulge it because } \\
\text { sometimes it is a fake NGO. }\end{array}$ & Check information veracity & Check information credibility \\
\hline 1 & $\begin{array}{l}\text { Get information because sometimes people come } \\
\text { asking for information about causes, but I don't } \\
\text { know the project. I like to divulge what I know } \\
\text { personally or there is someone very close who will } \\
\text { attest to me that the business is legal. }\end{array}$ & Knowing the social cause & Search information \\
\hline 1 & $\begin{array}{l}\text { The person has to make the influencer who will } \\
\text { divulge believe. You have to involve the person } \\
\text { who is going to divulge and make them believe. }\end{array}$ & Check source credibility & Check information credibility \\
\hline 2 & $\begin{array}{l}\text { I can support the proposal of any platform if it has } \\
\text { to do with literature, then it is within my scope. }\end{array}$ & Check post scope & Verify thematic distance \\
\hline 2 & $\begin{array}{l}\text { These are controversial issues that I try not to get } \\
\text { involved }\end{array}$ & Check controversies & Check polarization possibility \\
\hline 2 & $\begin{array}{l}\text { But when I support a culture-related campaign, } \\
\text { my risk is almost zero because I'm not getting } \\
\text { involved in controversial topics. What is my } \\
\text { goal? My goal is to sell books. I sell books } \\
\text { for "coxinhas" (supporters of the right field in } \\
\text { Brazilian politics), for "leftist", for socialists.. } \\
\text { What interests me is selling books. So I'm } \\
\text { not going to publish anything that makes me } \\
\text { uncomfortable with any group. I'm very careful } \\
\text { with that. }\end{array}$ & Check controversies & Check polarization possibility \\
\hline 2 & $\begin{array}{l}\text { If the person came with a briefing on what it is } \\
\text { about, they would already have detailed what the } \\
\text { objectives are, the target audience, so that I can } \\
\text { analyze the impacts of that on my career as an } \\
\text { author. If this was already "chewed", it would } \\
\text { be easier, it would give more agility and I would } \\
\text { certainly have another predisposition to publish. }\end{array}$ & Understand what will be divulged & Search information \\
\hline
\end{tabular}

Type 1 influencers also tend to limit their posts to the posting theme by which they are followed. Thus, there is a better chance for this type of influencer to post information on social causes that are related to his usual posting topic. Thus, to publicize a social cause, influencers with a small thematic distance should be chosen to increase the chances of posting.

On the other hand, type 2 influencers defend their ideas whatever that may be and that is expected by their followers. They are not afraid of losing followers. In most cases, they do not consider themselves digital influencers. So, it is just a matter of finding, trusting, and agreeing with the social cause to make these influencers post. It is interesting to notice that these people do not consider themselves influencers, just people that have many more followers than usual. Type 2 influencers may naturally post information on social causes they believe, even causing polarization among their followers. There is nothing to be protected in this case, besides the reputation of the influencer, only the veracity of the information. Next, we detailed our findings.

\subsubsection{Influencers are willing to post social causes}

We asked influencers their motivations for posting messages on social networks. The answers are related to maintaining the influencer-follower relationship. Four people said they were motivated by content sharing, two people to keep in touch with followers, and one person mentioned the 
recognition of followers. None of the respondents reported having financial motivations in the posts. Nevertheless, it is common sense knowledge that many public vloggers are part of the product marketing campaign and that they receive a great deal of money to talk about a product/idea. Possibly, the influencers who answered the questionnaire are not paid because they do not have a large number of followers. We emphasize here that influencers could point to more than one response option. The same applies to other questions.

We also asked about the strategies used by influencers to obtain, maintain, and increase the number of followers. According to their responses, their actions are mostly related to the content they post and their own qualification as an expert in a domain area. Three people answered the reasons for attracting followers are related to jokes, sarcasm, and pranks they post: their followers want to laugh. Two people said they are experts in a particular domain area. One person said he posted shocking information and one said that he posts contents to cultivate a network of friends. None of the influencers said they follow to be followed back. However, this is a common practice among many who want to increase their number of followers.

Concerning the topics covered in the postings, only one influencer cited four different subjects addressed in her posts. The five other influencers reported that they post only on one or two different subjects. This may be related to the fact that influencers are more likely to succeed when they speak directly and regularly, with a specific market niche. ${ }^{11}$ We were surprised to see that half of the respondents said that their posts are never related to their professional performance. Because they are small influencers, they can have other activities besides acting on social networks. Possibly, they responded thinking about this other activity. Half of the respondents said they do not know any social participation platform. In addition, among the other three interviewed that knew some citizenship platform, only one reported knowing a governmental platform. The two platforms of executive power (DialogaBrazil and Participa.br), created to meet the National Policy of Social Participation, are not known by the respondents.

Regarding the participation in social participation platforms, one of the respondents knew a platform, but never participated in it. Another respondent, who reported knowing only one platform, reported having already participated in this platform. Another respondent reported knowing three platforms and had already participated in all three. One of the three respondents who know a social participation platform reported participating frequently in these

platforms, while the other two reported participating sometimes. Of the three respondents who know of some social

\footnotetext{
${ }^{11} \mathrm{https} / / /$ www.impactbnd.com/blog/power-of-micro-influencers
}

participation platform, one never suggested to his followers to visit these platforms. The responses also show that a respondent often suggests his followers visit these platforms and others sometimes suggest. The influencer who responded who often suggests was the one who responded who knows more social participation platforms (knows three). Possibly, this higher recommendation rate is related to the greater interaction (and knowledge) that he has of these platforms.

The "socially engaged" influencers, which have already suggested others to visit a social participation platform, have either already received positive feedback from the followers, or no complaints so far. As we will mention later, the "after the questionnaire" interviewed followers informed they never give negative feedback to influencers, just stopped following them. The reasons for not posting information about social participation platforms, in most cases, are not related to the platform itself or to the content presented. The reasons are more related to the fact that the respondents post on other subjects and see no direct relationship between these platforms and the subjects of the posts. Perhaps these responses would be different for influencers who post about politics. Another reason presented as a reason for not posting content related to e-participation is laziness. It would take time and effort to check the information and to be sure the information would not harm the followers. Two respondents said they would not feel motivated to post on social participation platforms. The others have motivations related to what is being treated (either to pressure the government, stimulate discussion, give an opinion or defend a cause). The perceived advantages in sharing citizen behavior with followers range from the possibility of disclosure of the influencer's profile, the defense of what the influencer believes to be altruistic behavior (fostering citizen behavior in others and advocating a cause). The biggest disadvantage perceived by influencers in sharing their citizen behavior with their followers is personal exposure. It is interesting to note that, even with the importance that followers have for the influencer, none of them claimed to be afraid of losing followers. Most influencers believe that the people most affected by their posts about platforms would be those who are interested in politics (politicians, activists, and possibly minorities are included here).

In our previous work in which we did a systematic literature review [33], we noted there are 15 difficulties that lead to low participation in social participation platforms. In general, the technical difficulties are those that could be solved through technology. In our literature review, five technical difficulties were raised, which were presented as a response option in the questionnaire. In addition to these five, the option of the respondent to indicate another difficulty or to inform that he does not see a difficulty was 
also included. Our current findings are interesting since they identify issues that go beyond technical difficulties. The two respondents who already suggest the use of these platforms did not see any technical difficulties. Other respondents pointed out other difficulties, such as lack of transparency of the government ( 2 people), difficulty in using the platforms (1 person), and not seeing the result of their participation (1 person). In the systematic literature review, we observed ten non-technical difficulties that lead to low participation in social participation platforms. Non-technical difficulties depend on the will of the population. In addition to these ten difficulties, it was also included the option for the respondents to indicate another difficulty or to inform that they do not see a difficulty. We observed that, although three respondents did not know the participation platforms, the option "I do not know the participation environments" was not pointed out by any of the respondents. The answers were related to political issues, such as the lack of political interest, low confidence in politicians, or the discussion of topics that are far from the real needs of the citizen. Other personal difficulties were also presented, such as the difficulty in understanding the language used in participation platforms or even privacy issues. Regarding what could be shared by the influencer, only two reported that they would not share anything about participation platforms. The other four would do platform-related shares ( 2 people, link to the platform; 1 person, criticizes the content of the platform; 1 person, vote or comment).

\subsubsection{Influencers perceive high costs to post social causes}

The first interviewee (Interviewee1) is a 30-year-old male participant that posts about trips. He has about 116,000 followers on Instagram and 89,000 on YouTube. Interviewee2 is a 57-year-old male participant, an information systems manager in a hospital, and a thriller book writer. He has approximately 30,000 followers on Facebook. Both respondents are present on various social networks. However, they have different preferences for some social networks. Interviewee1's sentence shows that there is a necessary effort before posting, which will be further explored throughout this subsection. Interviewee1 said "My frequency is higher on Instagram because it requires less writing effort. Posting a photo is simpler."

We asked if the interviewees knew any platform of social participation. Both respondents responded positively. Interviewee 1 also mentioned that he already shared a petition. He said: "I believed in the theme and more people could also believe in the theme, take notice and complete the goal faster." This shows that the influencer may be interested in posting social causes. However, the influencer may also perceive costs to make this post. Interviewee 2 said he never posted about these platforms on social networks. He said "I try not to mix the two things. I deal with literature." From that comment, we came to the code "check post scope" on the axial codification. Interviewee 2 also said that he could support some cause related to literature, but he does not get involved in controversial issues. This statement showed that there is a cost (code) "check controversies." He continued: "There are artists who are deeply engaged, and you see that engagement, but in my case I try to be neutral. I try not to lose readers." In this comment, we identified the code "check audience reaction."

Interviewee1 said he would release petitions related to tourism. "It's a cause or something related to my audience," showing that there is a "check followers' interest" cost. On posting causes that are not related to tourism, Interviewee1 said "I am very careful to divulge because sometimes it is a fake NGO. It generates a job of having to check, it's complicated." Therefore, the influencer realizes the cost of "check information veracity."

We asked if the influencer believed it was possible to lose followers due to publication on social causes. Interviewee1 said "depends on the theme. You will further segment your audience and will eliminate people who are not in line with your speech." In this phrase, we identified the code "understanding followers profile."

We asked about laziness to make a post. Both influencers said the biggest difficulty is the time it takes to get information about a cause before posting. Interviewee1 said, "Sometimes people ask to post about causes, but I do not know the project. I like to post what I know personally or have someone very close that will attest that the business is legal." In this phrase we identified the code "knowing the social cause." He said he had "to analyze to see if it was worth it or not because it involves credibility. Credibility is only lost once," we then identify the code "check source credibility." Both influencers believe that this cost would be reduced if they received a briefing with information on the cause before post. Interviewee 2 said that he should receive "detailed what the objectives are, the target audience so that I can analyze the impacts of that in my career as an author. If it had already 'chewed,' it would have been easier, it would have been more agile and I would certainly be more willing to publish". In this comment, we identified the code "understand what will be divulged."

Based on the codes identified in the axial coding (check post scope, check controversies, check followers' interest, check information veracity, understanding followers profile, knowing the social cause, check source credibility, understand what will be divulged, check audience reaction), we tried to understand what was happening, that is, why the interviewees perceived these costs (codes). We realized then, in selective coding, that the codes "check information veracity" and "check source credibility" could be understood as the cost (code) "check information credibility." The 
codes "check audience reaction," "understanding followers profile," and "check controversies" happened due to the cost of "check polarization possibility." The "check followers' interest" and "check post scope" costs were due to the need for " check polarization possibility." The costs of "knowing the social cause" and "understand what will be divulged" could be summarized in the cost (code) "search information." Therefore, we can summarize the costs (codes) found in the interviews into four costs (codes) in selective coding: search information, check information credibility, verify thematic distance, check polarization possibility.

\subsection{Followers}

\subsubsection{Followers can participate in social causes from the recommendation of influencers}

In an increasingly fragmented media environment, information shared by opinion leaders may be more influential as people increasingly rely on suggestions and information provided by others in their social network [34] and tend to rely on it more information than when received directly from the media [35]. Given that 19 people reported that they follow a profile to inform themselves, from the answers, it is possible to observe that the content posted is fundamental in the decision to follow a profile (19 people said they follow a profile because they like what is posted, 16 people also said to follow by agreeing with what is posted). Six people claimed to follow the person's reputation and 20 people stated that friendship matters. Almost all followers have stated that they read and like the posts of their influencers. Thirteen of the 27 respondents said they share the influencer's posts. This is important information because it can help in the diffusion of a post about a participation platform that is published by the influencer. It is also important to note that 15 of the 27 respondents access the sites divulged by the influencers, which could lead the follower to the platform of participation if it were publicized by the influencer.

Only 3 respondents stated that they did not change their habits because of influencers' posts. The answers showed that 24 of the 27 respondents changed or could change their habits according to the posting of the influencer. Only 6 of the 27 respondents do not know of any social participation platform. It can be observed that the most well-known platforms of the respondents are nongovernmental platforms (Amnesty International, Avaaz, Change.org, and Votenaweb). The minority of respondents know governmental platforms (Dialoga Brazil, Participa.br, and Legislative Idea). Bicking et al. [36] state that there is a lack of strategy for publicizing e-participation projects in social networks that leads to a low audience on the platforms of these projects. The interviews we conducted also showed that both influencers and followers could not name the platforms for participation. However, every time respondents participated, in these platforms, they were informed from a post on social networks. Among the respondents, the main reason for not having used a platform is unawareness of the existence of the platform. This is the problem we intend to address by publicizing the platforms through influencers. Another reason that has also been cited is mistrust. Eighteen of the 27 respondents have already participated in social participation platforms due to the suggestion of another person. This information is important because it shows openness to receiving (and accepting) a recommendation. This raises the expectation that the use of these platforms can be extended with more people becoming aware of these platforms through recommendations in social networks. Fifteen people stated that they would invite others to mobilize more people (certainly because they agreed with the causes under discussion). Two people even said they would share something posted by someone they follow. This may be related to the credibility of the influencer.

If the influencers believe that personal exposure is a disadvantage when posting that they participated in a social participation platform, 14 followers (out of 27 respondents) said they would like to know what the influencer participated in. Another 9 respondents could also participate ( 1 would engage if they agreed and another 8 affirmed that they possibly would participate too). Only one person said he would find it bad if the influencer stands for a position different from hers. However, three people said they would stop following the influencer if they disagreed with their position. Only one person stated that he would think it bad for the influencer to state that he participated in the platform (regardless of the position advocated by him) and two people said they were indifferent. The major reason the follower accepts the influencer's recommendation and participate in these platforms is related to the subject being addressed. Twenty-one people said they would accept the suggestion because of the importance of the subject under discussion. Seventeen followers said they would recommend participating in the platform to their contacts in social networks to get more support for the cause. This is important in the context of our work since the aim is to promote social participation platforms. Thirteen people would make this recommendation to stimulate the discussion of the subject being treated. Only two people said they would not recommend it and five would recommend it.

\subsubsection{Followers can stop following influencers if they disagree with their posts}

Interviewee1 is a 34-year-old woman and holds a Ph.D. in chemistry. She follows 50 people on Instagram and 20 
on Twitter. Interviewee 2 is a 30 -year-old woman and is a medical student. She follows 1015 people on Instagram and 820 on Facebook. Interviewee3 is a 29 -year-old man who is a doctor. He follows only 19 people on Instagram. We asked about the reasons for following a profile on social networks. Interviewees 1 and 2 said that they follow different people in each social network. Interviewee1 said, "on Twitter I follow more to keep me updated. Like an electronic magazine. So, the influencers there are more like that, I follow more magazines, newspapers, people connected to politics, you know? In Instagram no, there is another bias like that more futile, it is leisure." Interviewee3 said he acts the same way. He said, "the profiles I follow in Instagram are only related to medicine, medical institutions." We asked about what matters when deciding to follow a profile. The three interviewees said that what matters in deciding to follow someone is the published content. "I see if the content fits my profile," said Interviewee1.

We asked interviewees what they would find if the influencer pass to divulge social causes. Interviewee2 said, "I think it's good because if she has divulged a cause that interests me, I'll respect her more as a digital influencer. But if she divulges what I do not like, for example, I'll probably stop following." She has already supported the causes she has known from social networks. She also said she would talk to her friends not to follow an influencer who defends a cause she disagrees with. Interviewee1 said that she would support the causes "if it was in accordance with my ideas as well." The three interviewees said they would no longer follow the profile if they disagreed with the position advocated by the influencer. Interviewee 2 said she divulges to her friends those influencers who talk about social causes that she agrees. She said that she does it "because they are matter that interests me and I divulge it to people that I know will be interested too and who do not know the influencer."

When asked if they would follow an influencer who advocates the same causes as them, Interviewee2 said, "I would probably see his profile, analyze and follow him." Interviewee1 said, "I would not follow for an isolated cause that I am in favor," but that she would follow the influencer if she identified with several causes defended by him. Interviewee 3 would not follow the influencer by agreeing to the causes he advocates. We asked if they have already signed petitions published on social networks. The three interviewees responded yes. However, they have never directly accessed the platforms. Interviewee1 said that the influencer is "an intermediary, a disseminator." The three interviewees said they become aware of causes through social networks but participate when agreeing to the causes.

\section{Discussion}

In this work, we had as objectives to verify if the influencers would accept to publish civic content in their social media and how the followers would react to these posts. We could verify that there is a possibility that the influencer accepts to divulge social causes. Knowing that there is a possibility for influencers to take their followers to social participation platforms, we seek to understand what the costs (onus) are for this. Influencers who have already recommended participation on these platforms reported never having received criticism from followers. On the other hand, in questionnaires and interviews, the followers reported not giving negative feedback to influencers. They simply stop following the profile. This poses a risk to influencers when engaging in causes that may displease part of their audience. However, most followers said they would like to know about influencer's citizen behavior. This shows that the ideal is for the influencer to post only social causes that have broad support from his audience and avoid controversial causes.

The interviews also showed that the causes related to the influencer's posting theme could get more support from these influencers. The main concern of influencers is to lose their credibility (and therefore their followers). Therefore, they do not divulge causes that they do not know. This makes it a great job for them to get informed before posting. The interviews showed that a reduction in this work would lead them to post more about social causes. The influencers said that the way to reduce this cost would be to provide them with a summary of the project/cause that they should post.

In summary, we can point to four important factors to design the cost-structure function of influencers posting behavior: (1) Search information: without knowing the social cause and the existence of social participation platforms, the influencer cannot recommend participation to his followers. (2) checking thematic distance: the distance between citizenship topics and the topics the influencers are used to post. Analogously, to social distance [37], we can measure the distance between the influencer's usual post domain and a civic domain. We believe the 6 degrees of separation will hold it here too. This is one of our future work. We believe these findings might mitigate the fear influencers has to lose their followers. (3) Check polarization possibility: some posts may displease followers. This happened to one of the interviewees who stated "I had a controversial post, which was dropping lanterns in Thailand, which had pro-environment people who had a speech about the environment." Again, the fear of losing their followers might prevent influencers to state 
their opinion. This result is in line with that presented in different reports, e.g., an Australian influencer who lost followers because of a post that displeased them. ${ }^{12}$ Another Australian influencer also lost followers after promoting products during the COVID-19 pandemic. ${ }^{13}$ These results can be even more noticeable at times like the COVID-19 pandemic, ${ }^{14}$ when many followers are at home and follow influencers' posts more closely. (4) Check information credibility: influencers know their post might get people to follow and to attribute influencers as responsible. When they are paid for as an ad, the tradeoff is clear. When there is no money involved, when it is a civic duty, influencers must verify the veracity of information before spreading it around. According to interviewees, this is the biggest cost for influencers since they can lose their credibility. This is a technical issue that information systems might address.

In the responses obtained through the questionnaire sent to followers, we observed that the relevant influence processes (regarding social influence theory [38]) in the context of social participation platforms are identification and internalization. This could be observed when respondents reported that they are led to follow a profile in social networks by the relationship of friendship (or other relation) that has with the influencer (occurring then the process of social influence by identification). Responses presented as reasons for following a profile are related to the internalization process. It is the case of people who claimed to follow a profile because they like the content that is posted or follow due to the reputation of the person. Regarding those people who said they follow a profile to get informed, they could seek information elsewhere (or other profiles), but the choice for a particular profile may be related to the credibility they see in that profile. No responses related to the compliance process (one of the three processes of social influence) appeared.

If, on the one hand, the decision to follow a profile is related to both the identification process and the internalization process, the same does not happen when it comes to accepting the recommendation of the influencing profile. When asked what would lead the follower to accept the recommendation and participate in social participation platforms, only one person said she would

\footnotetext{
$\overline{12 \mathrm{https} / / / \mathrm{www} .}$ intheknow.com/2020/05/07/influencer-breaks-down-ov er-lost-followers/

${ }^{13}$ https://www.dailymail.co.uk/tvshowbiz/article-8305961/InfluencersWAGS-losing-thousands-Instagram-followers-day-amid-coronaviruspandemic.html

${ }^{14}$ https://www.ft.com/content/c35ca1d6-9c3e-11ea-871b-edeb99a20c6e
}

accept the recommendation to help the influencer get more participants. Five people responded that they would accept due to agreeing to most of the influencer's ideas. On the other hand, many followers have indicated options related to the internalization process (agree on the subject). Twenty-one people $(77.8 \%)$ said they would accept the recommendation because of the importance of the subject for them. This also agrees with the social influence theory, which states that an important goal must be activated so that the individual accepts the influence.

Concerning the followers inviting other people from their social networks to participate in the social participation platforms, only two followers (7.4\%) reported that they would invite others because they were divulged by someone they follow. The internalization process appears here. Twenty-one followers (77.8\%) said they would invite others because they agree with what is being addressed. Eighteen followers $(66.7 \%)$ would invite others to participate because they considered the issue important. Fifteen people (55.6\%) would invite others to mobilize more people for (or against) a cause. Ten people (37\%) would invite others from their social network to participate in something advocated by a specialist. These results give the impression that people accept the influence both by the identification process and by the internalization process when the acceptance of that influence affects only them. However, they carry this influence to their contacts in most cases when they have been influenced by the process of internalization (that is, they agree with the content of the influence and not only identify with the influencer).

From the interviews and questionnaire' analyses emerged our understanding of the cost structure for the posting behavior of influencers, shown in Fig. 3. The cost of posting is a function of the influencers' intention to post and the physical aspects (availability of time, Internet access, and the writing itself). The intention is affected by the possibility of gains (monetary or not) and by the efforts involved in finding the information, checking the veracity of the information, understanding the followers' profile, and the impact on them of posting something different from the usual content.

As noted in Oliveira and Bicharra Garcia [33], ignorance of the possibilities of participation in government platforms is one of the reasons why citizens do not participate. In the interviews we conducted with the followers, they reported that they became aware of the possibilities of participating through posts on social networks. As influencers have an audience on social media, they could publicize these participation initiatives to their followers. This would solve one of the reasons for not participating. In this paper, 
Fig. 3 The cost structure of posting behavior

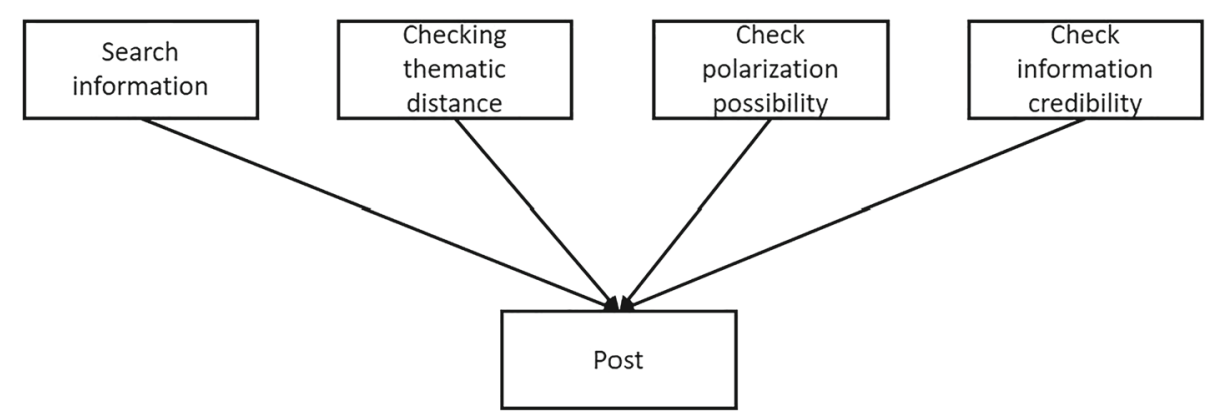

we present the costs for influencers to post social causes. Governments (or other institutions that want to publicize social causes) could use this information to choose those influencers who would have the lowest cost (and greatest chance) of posting.

\section{Conclusion and future work}

As presented in this paper, despite the possibilities for electronic participation created by governments, citizen participation is still very small. One of the reasons for this is that many times the citizen does not even know about the possibility of participating. A strategy for disseminating platforms and initiatives for participation in social networks is lacking [36]. This divulges could be made by digital influencers, who already have an audience on social networks.

The questionnaires and interviews showed us that, despite participating in social participation platforms, people remember the causes, but not the platforms. According to the interviews, those who participated did not directly access the platforms. They became aware of a cause through a social networking post. This shows the importance of posting on social networks. These social causes can be widely disseminated through digital influencers. However, these influencers do not want to post on controversial issues. They prefer to post about causes related to their posting themes. However, influencers care about their credibility. Thus, they do not post on causes they do not know. Getting information about a cause takes a lot of time from the influencer, and it is the big cost that inhibits posts about social causes. The main contributions of this work are as follows: (1) The understanding of citizen e-participation and how to make use of influencer as a powerful tool to promote digital citizenship; (2) it helps in understanding posting behavior.

This work has some limitations: (1) Getting influencers who wanted to participate in the interviews/questionnaires in this research was quite difficult. It is possible that other observations can be made with the expansion and/or diversification of the set of influencers interviewed. Therefore, this work does not intend to present results that can be generalized. The results obtained must be considered for influencers with characteristics similar to those interviewed in this work; (2) this work identified a cost structure that can be automated to minimize the influencer's risks and maximize the chances of a post happening. However, in this work, no systems were developed to perform this automation. This is a possibility for future work; (3) the focus of this work was on posting social causes. However, there are still questions to be answered for commercial postings in future work.

\section{Appendix 1: Questionnaire used with influencers}

In this subsection, we present the questions and answer options of the questionnaire presented to the influencers.

Q1: What motivates you to post messages on social media?

1. I get paid for it

2. I like to keep in touch with my followers

3. I like to share knowledge

4. I want to increase my sales

5. Other

Q2: What do you do to have followers?

1. I follow others to be followed back

2. I make controversial posts

3. I'm a specialist in a certain area

4. I make funny posts

5. I pay to have more followers

6. I post impactful information

7. Other 
Q3: Inform what subjects are covered in your posts.

1. Politics

2. Fashion

3. Gastronomy

4. Travel

5. Health

6. Sale of products / services

7. Anything

8. Other

Q4: How often are your posts related to your professional performance? (Likert scale from 1 to 5). 1. Never, 5. Always.

Q5: What social participation platform do you know about?

1. Ideia Legislativa

2. Participa.br

3. Dialoga Brasil

4. Votenaweb

5. Change.org

6. Avaaz

7. Participatory budgeting platforms

8. Amnesty International

9. None

10. Other

Q6: What social participation platforms have you participated in?

1. Ideia Legislativa

2. Participa.br

3. Dialoga Brasil

4. Votenaweb

5. Change.org

6. Avaaz

7. Participatory budgeting platforms

8. Amnesty International

9. None

10. Other

Q7: How often do you usually share your interactions with government websites on your social network, whether for tips or criticisms?

1. Often

2. Sometimes

3. Rarely

4. Never

Q8: Have you suggested in your social networks to visit a site of social participation?

1. Often

2. Sometimes

3. Rarely

\section{Never}

Q9: If you have already suggested visiting a website, what was the reaction of your followers?

1. I received criticism

2. I received support

3. I received praise

4. No reaction

5. I never suggested anything

6. Other

Q10: What are the reasons why you avoid sharing this type of information (suggestion from sites)?

1. It is not the topic I usually post

2. Laziness

3. I don't trust what I read

4. Consistency with what I usually post

5. I'm afraid of losing my followers

6. I don't like controversy

7. There is no impediment

8. Other

Q11: What would motivate you to share your citizen behavior with your followers?

1. Defend a cause

2. Give an opinion about something

3. Stimulate discussion of a subject

4. Pressure the government

5. I do not know

6. I prefer not to share

7. Other

Q12: What advantages do you see in sharing your citizen behavior with your followers?

1. Promote my profile on social networks

2. Spread my ideas

3. Financial advantage

4. Defend a cause

5. Encourage citizen behavior in others

6. Other

Q13: What disadvantages do you see in sharing your citizen behavior with your followers?

1. Personal exposure

2. Being judged by my ideas/behavior

3. Lose followers who disagree with what I posted

4. Juridical insecurity

5. I don't see any disadvantage

6. Reprisals

7. Other

Q14: Who do you think would be affected by your posting (entering government websites to get information, 
participating in social discussions and even voting on government websites)?

\section{Politicians}

2. Citizens who are interested in politics

3. Citizens who are activists of some cause

4. Minorities

5. Any follower

6. Journalists

7. Other influencers

8. Anyone

9. Nobody

10. Other

Q15: What technical difficulties do you perceive to access social participation sites?

1. Lack of accessibility (for people with some type of disability)

2. Difficulty accessing the Internet or IT equipment

3. Lack of government transparency

4. Not seeing the result of my participation in government acts

5. Difficulty in using government environments

6. No difficulty

7. Other

Q16: What non-technical difficulties do you perceive for you to access social participation sites?

1. Difficulty understanding the language used in government environments

2. Topics discussed in government environments are far from the needs of the citizen

3. I do not know the participation environments

4. Privacy issues

5. Many political actors with different interests

6. I only access the sites, but I don't participate

7. Lack of political interest

8. I don't want to produce content or give feedback about these sites

9. Low confidence in politicians

10. I have more enthusiasm for the site itself (technology) than for the subjects covered in it

11. No difficulty

12. Other

Q17: If you wanted to share your citizen behavior, what would you share?

1. Link to website

2. Your vote or comment, etc.

3. Criticizes the content of the site

4. Praise about website content

5. A summary of what's in there

6. Nothing (wouldn't share)
7. Other

\section{Appendix 2: Questionnaire used with followers}

In this subsection, we present the questions and answer options of the questionnaire presented to the followers.

Q1: What makes you follow a profile?

1. My friendship (or other relationship) with the person

2. Help the person to have more followers (boost the profile)

3. Person's reputation

4. Agree to what the person posts

5. I like the content that is posted

6. Track/monitor a person

7. To inform me

8. I do not know

9. Other

Q2: How do you usually interact with the posts of the person you follow?

1. Read

2. Like

3. Comment

4. I share with my contacts

5. I click on the link (if any)

6. Other

Q3: Would you change your habits or opinions as a result of posting someone you follow?

1. I've changed

2. Maybe

3. No way

4. Other

Q4: What social participation platform do you know about?

1. Ideia Legislativa

2. Participa.br

3. Dialoga Brasil

4. Votenaweb

5. Change.org

6. Avaaz

7. Participatory budgeting platforms

8. Amnesty International

9. None

10. Other

Q5: What social participation platforms have you participated in?

1. Ideia Legislativa 

2. Participa.br
3. Dialoga Brasil
4. Votenaweb
5. Change.org
6. Avaaz
7. Participatory budgeting platforms
8. Amnesty International
9. None
10. Other

Q6: If you have not participated in any participation platform, say why.

1. Unfamiliarity

2. Laziness

3. I don't believe that my participation will change anything

4. I consider the subjects treated irrelevant or distant from my needs

5. I don't trust politicians

6. I don't trust the sites

7. Other

Q7: Did you participate on someone else's recommendation?

1. Yes

2. No

3. I never participated

Q8: What would make you invite other people from your social network to participate?

1. Agree to what is being treated

2. Having been publicized by someone I follow

3. Something advocated by an expert on the subject

4. Consider the matter important

5. Mobilize more people for (or against) a cause

6. Other

Q9: What would you think if someone you follow informed on social media that they participated in such a platform?

1. It would be bad for people to report it on social media
2. I would think it was bad if the person made a political demonstration

3. Would I think it was bad if she defended a position contrary to mine

4. I would like to know that the person participated

5. I would like to know that the person participated, depending on how they positioned themselves

6. I would stop following that person

7. I would stop following if I disagreed with the position defended by her

8. I would post/share on my social networks

9. Possibly, I would also participate

10. Other

Q10: What would lead you to accept the recommendation of those you follow and participate in these platforms?

1. Agree to most of that person's ideas

2. Agree to the matter at hand

3. Help that person get more participants

4. Importance of the subject for me

5. Pressure the politicians

6. Believing that this person's support for the cause will make a difference

7. Other

Q11: Comment on what would lead you to recommend participation in a government platform for your contacts on social networks.

1. Help get more support for a cause I agree with (or against a cause I disagree with)

2. Stimulate discussion of the subject

3. Disseminate my opinion

4. Create controversy

5. I would not recommend

6. Other

\section{Appendix 3: Data used in coding}

In this subsection, we present the stages of coding carried out in this work.

Table 5 Coding of data presented in the results for Interviewee 1

Statements highlighted as tasks in the open coding phase

Suppose you have a petition to build an artificial fund in Marica (city in Rio de Janeiro). I found it super interesting because it will promote tourism, it will bring economic opportunities. This is a petition that I would post on my Instagram, which I think is valid. It is a cause or something related to my beliefs and also related to my audience.
Codes generated in
the axial coding
phase

Check followers' interest
Main category assigned in the selective coding phase

Checking thematic distance 
Table 5 (continued)

I have already divulged the social cause of an acquaintance from Africa, who is building a school. But I am very careful to divulge it because sometimes it is a fake NGO.

And then it creates a job for me to have to check, it's complicated.

There are many people who do this with a hidden agenda, to take advantage of society's trends and take an opportunity to be the defender of the cause.

Every time you take a position, there are two possible outcomes: you either lose or you win. When you expose your thinking. This is good and bad too because you will segment your audience even more and you will eliminate people who are not aligned with your speech.

I already had a controversial post, which was dropping lanterns in Thailand, which had pro-environment people who had a speech about the environment. And they criticized, but they were also not perfect models to be followed. Only, when criticizing, they gained followers too. They were tied to that idea. But I also had people, my followers, who understood the message, which was much bigger than that part.

I try not to get into politics. Even more because of the moment that we are living today, which is complicated. So I try to show what a non-partisan citizen is, which would be the minimum for anyone, be it from the right, left or any political spectrum.

Why we do not know what people want as well. We post a lot that we don't know if the person wants it or not. Having feedback that this is interesting and relevant to a large part, or even a smaller number, we can post more.

I collect feedback to adjust my content to what people want to see.

I have to please them because without them I am no one there on social media. It's an exchange. I'm generating content for them, for the audience. They are the customers.

My strategy on Youtube is a content strategy that will help people who are traveling and want to know more about the destination. Or about camera equipment, which is another aspect of my channel. On Instagram we make content with other people and you get exposure with the audience of someone else who has related content. This works too much. We cross-refer on Instagram. Yesterday I participated in collaboration with another person that goes to Youtube. These are people who have very interesting content, relevant to my audience and I have it for their audience. Then there will be an exchange of followers.

We took a trip together and we had a great exchange of followers because our content was crossed. There were two different views, mine and hers. So the person may want to see the same content from different perspectives. In one case, I am the interlocutor and she has a secondary role. And on her channel the opposite.

We expose ourselves to anything we do. In any stories, we are exposing ourselves. I don't think we are exposing ourselves more or less because we are promoting such a business. I think it is the same as any idea that we will share through social networks. It is not because it is a social cause that you are exposing yourself more or less.

Get information because sometimes people come asking for information about causes, but I don't know the project. I like to divulge what I know personally or there is someone very close who will attest to me that the business is legal.
Check information

veracity

Check information credibility

Check information veracity

Check audience

reaction

Understanding followers profile

Check information credibility

Check polarization possibility

Check polarization possibility

Check

controversies

Check polarization possibility

Check

controversies

Check polarization possibility

Understanding followers profile

Check polarization possibility

Understanding followers profile

Check followers' interest

Check followers' interest

Check polarization possibility

Checking thematic distance

Checking thematic distance

Check followers' interest

Checking thematic distance

Check audience reaction

Check polarization possibility

Knowing the social cause
Search information 
Table 5 (continued)

When you refer someone or something, it is your reputation that is at stake. It is very dangerous to indicate what you do not know. The same is true with companies. I receive a lot of travel agencies asking me to make the referral in exchange for a commission. I already said that I couldn't do this because I didn't know the company's service. I have to try the service and analyze it to see if it's worth it or not, because it involves credibility. Credibility is only lost once.

The person has to make the influencer who will divulge believe. You have to involve the person who is going to divulge and make them believe.
Check source credibility

Check information credibility
Check source credibility
Check information credibility

Table 6 Coding of data presented in the results for Interviewee 2

Statements highlighted as tasks in the open coding phase

I try not to mix things up. I deal with literature

I can support the proposal of any platform if it has to do with literature, then it is within my scope.

These are controversial issues that I try not to get involved

I usually advertise campaigns for young people in search of dreams. There are young people wanting to publish books, there are young people wanting to make a trip to study abroad. This I support. Because it's about culture. I support everything that is aligned with the culture.

But when I support a culture-related campaign, my risk is almost zero because I'm not getting involved in controversial topics. What is my goal? My goal is to sell books. I sell books for "coxinhas" (supporters of the right field in Brazilian politics), for "leftist", for socialists.. What interests me is selling books. So I'm not going to publish anything that makes me uncomfortable with any group. I'm very careful with that.

There are artists who are deeply engaged, and you see that engagement, but in my case I try to be neutral. I try not to lose readers.

We as an author, we already suffer a lot with the interpretations. You write a sentence and give it to someone else to read, possibly that person will give you another interpretation of what you wrote. So there is naturally a loss of meaning at each reading. The moment you are going to mix a component of your private life, your political positions, I believe it will contaminate your text. I try not to mix.

If the author gets involved in a political issue, you will surely displease $50 \%$. And in that you may be losing readers. For established authors, this can represent $0,1 \%$. In my case, that I am still looking for a place in the sun, any reader will be missed.

By the time you are faced with information like this, from someone asking for support for a certain cause, you have read. You already informed.

If it had already come "chewed", without a doubt it would be halfway there. It would reduce the cost.
Codes generated in

the axial coding

phase

Check post scope

Check post scope

Check

controversies

Check post scope

Check

controversies

Check audience

reaction

Check

controversies

Check

controversies

Understand what will be divulged

Understand what will be divulged
Main category

assigned in the

selective coding phase

Checking thematic distance

Checking thematic distance

Check polarization possibility

Checking thematic distance

Check polarization possibility

Check polarization possibility

Check polarization possibility

Check polarization possibility

Search information

Search information 
The biggest cost is to have detailed information about what you are getting involved in

If the person came with a briefing on what it is about, they would already have detailed what the objectives are, the target audience, so that I can analyze the impacts of that on my career as an author. If this was already "chewed", it would be easier, it would give more agility and I would certainly have another pre-disposition to publish.

The more information you have to make the decision, the better.
Knowing the social

cause

Understand what

will be divulged
Search information

Search information

Search information

\section{References}

1. Chatterjee P (2011) Drivers of new product recommending and referral behaviour on social network sites. Int J Advert 30(1):77101

2. Ferro E, Molinari F (2010) Making sense of Gov 2.0 strategies: "No citizens, no party". JeDEM 2(1):56-68

3. Tolbert CJ, Mossberger K (2006) The effects of e-government on trust and confidence in government. Public Adm Rev 66(3):354 369

4. Araujo RM, Maciel RS, Boscarioli C (2017) I GranDSI-BR: Grandes Desafios de Pesquisa em Sistemas de Informação no Brasil (2016-2026) - Relatório Técnico. Comissão Especial de Sistemas de Informação (CE-SI) da Sociedade Brasileira de Computação (SBC). 67p, ISBN 978-85-7669-359-8

5. Howard M (2001) E-government across the globe: how will'e'change government. e-Government 90:80

6. Chandler S, Emanuels S (2002) Transformation not automation. In: Proceedings of 2nd european conference on E-government, pp 91-102

7. Layne K, Lee J (2001) Developing fully functional E-government: A four stage model. Gov Inf Q 18(2):122-136

8. United Nations - DPEPA (Division for Public Economics and Public Administration) (2002) Benchmarking E-Government: a global perspective, http://pti.nw.dc.us/links/docs/ASPA_UN_ egov_survey.pdf

9. Macintosh A (2004) Characterizing e-participation in policymaking. In System Sciences, 2004. In: Proceedings of the 37th annual Hawaii international conference on. 10-pp. IEEE

10. Caddy J, Vergez C (2001) Citizens as partners: Information, consultation and public participation in policy-making. Organisation for Economic Co-operation and Development PUMA Working Group on Strengthening Government-Citizen Connections

11. Cunha MAVCD, Rosina MSG, Teixeira MAC, Silva APD, Lazzari EA, Silva MCFD, Cruz B (2015) Experiências governamentais brasileiras de participação digital. Escola de Direito de São Paulo da Fundação Getulio Vargas. Grupo de Ensino e Pesquisa em Inovação

12. Pinheiro B (2017) Plataformas de democracia eletrônica: um retrato para gestores públicos. X Congresso Consad de gestão pública

13. Gomes W (2005) Internet e participação política em sociedades democráticas. Revista Famecos: mídia, cultura e tecnologia, (27)

14. Cruickshank P, Edelmann N, Smith C (2010) Signing an e-petition as a transition from lurking to participation na

15. Crossley N (2010) The social world of the network. Combining qualitative and quantitative elements in social network analysis. Sociologica 4(1):0-0

16. Moreno JL (1934) Who shall survive?: A new approach to the problem of human interrelations
17. Bakshy E, Hofman JM, Mason WA, Watts DJ (2011) Everyone's an influencer: Quantifying influence on twitter. In: Proceedings of the 4th ACM WSDM

18. Sanchez-Cartas JM, Leon G (2018) On "Influencers" and their impact on the diffusion of digital platforms. In: International conference on practical applications of agents and multi-agent systems. Springer, Cham, pp 210-222

19. Cheung CM, Thadani DR (2012) The impact of electronic wordof-mouth communication: A literature analysis and integrative model. Decis Support Syst 54(1):461-470

20. Neves A, Vieira R, Mourao F, Rocha L (2015) Quantifying Complementarity among Strategies for Influencers' Detection on Twitter1. Procedia Comput Sci 51:2435-2444

21. Kolo C, Haumer F (2018) Social media celebrities as influencers in brand communication An empirical study on influencer content, its advertising relevance and audience expectations. J Digit Soc Med Market 6(3):273-282

22. Page L, Brin S, Motwani R, Winograd T (1999) The pagerank citation ranking: Bringing order to the web. Technical report, Stanford InfoLab

23. Ilyas MU, Radha H (2011) Identifying influential nodes in online social networks using principal component centrality, IEEE

24. Silva A, Guimarães S, Meira WJr, Zaki M (2013) Profilerank: Finding relevant content and influential users based on information diffusion. In: Proceedings of the 7th SNAKDD. ACM

25. Lee C, Kwak H, Park H, Moon S (2010) Finding influentials based on the temporal order of information adoption in twitter

26. Wu S, Hofman JM, Mason WA, Watts DJ (2011) Who says what to whom on Twitter. In: Proceedings of the 20th WWW

27. Yang L, Sun T, Zhang M, Mei Q (2012) We know what you \#tag: does the dual role affect hashtag adoption?, ACM

28. Charmaz K (2014) Constructing grounded theory. Sage, Singapore

29. Strauss A, Corbin J (1998) Basics of qualitative research techniques. Thousand Oaks, Sage publications

30. Strauss A, Corbin J (1990) Open coding. Basics of qualitative research. Grounded theory procedures and techniques 2(1990):101-121

31. Engward H (2013) Understanding grounded theory. Nurs Stand $7: 28$

32. Ajzen I (1991) The theory of planned behavior. Organ Behav Hum Decis Process 50(2):179-211

33. Oliveira C, Garcia AC (2019) Citizens' electronic participation: a systematic review of their challenges and how to overcome them. Int J Web Based Commun 15(2):123-150

34. Mutz DC, Young L (2011) Communication and public opinion: Plus ça change? Public Opin Q 75(5):1018-1044

35. Marwick AE, Boyd D (2011) I tweet honestly, I tweet passionately: Twitter users, context collapse, and the imagined audience. New Media Soc 13(1):114-133 
36. Bicking $\mathrm{M}$ et al (2011) Lessons from monitoring and assessing EC-funded eParticipation projects: citizen engagement and participation impact. In: IST-Africa conference proceedings, IEEE, pp 1-8

37. Boguná M et al (2004) Models of social networks based on social distance attachment, vol 70
38. Kelman HC (1958) Compliance, identification, and internalization three processes of attitude change. J Confl Resolut 2(1):51-60

Publisher's note Springer Nature remains neutral with regard to jurisdictional claims in published maps and institutional affiliations. 